\title{
BCCM4
}

\section{MECHANICAL ANALISYS OF POLYMERIC WEBBING TESTS WITH AND WITHOUT PRELOADS}

\author{
Andrés Heemann Pereira Neto ${ }^{(1)}$, Filipe Paixão Geiger ${ }^{(1)}$, Tales de Vargas Lisbôa ${ }^{(1)}$, \\ Rogério José Marczak ${ }^{(1)}$
}

(1) Department of Mechanical Engineering, Universidade Federal do Rio Grande do Sul, Brazil

https://doi.org/10.21452/bccm4.2018.05.04

\begin{abstract}
The paper aim is the characterization of the mechanical behavior of webbings when exposed to multiple preloads and the comparison with the Mullins Effect. Since the webbings presents a non-linear behavior difficult to predict, the tests themselves are important to specify its mechanical response. The webbings are combinations of Polyester, Nylon, UHMWPE and other composites. The experiments were performed based on ASTM D6775 and WSTDA-TM-1, however it is highlighted the lack of standardization considering the type of material, therefore a methodology was proposed to perform the tests. The results showed that after an application of 3 preloads of $70 \%$ of the rupture load the webbing behavior remains unchanged as well as the rupture load. Two limits are noticeable, the lower (without preload) and the upper (with 10 preloads) limits.

Keywords: Webbing, Polymer, non-linear, experimental.

\section{INTRODUCTION}

The webbing, considering its material and geometry (shown in Figure 1), presents a nonlinear mechanical response in the traction test. Its manufacture results in voids and nonhomogeneities that make it difficult to determine the real area to be used in strains and stresses, besides influencing the test. These webbings have combinations of materials, such as: Polyester, Nylon, UHMWPE and other polymeric fibers. Consequently, the final composite behaves differently from the original constituent by itself ([3] and [4]).
\end{abstract}




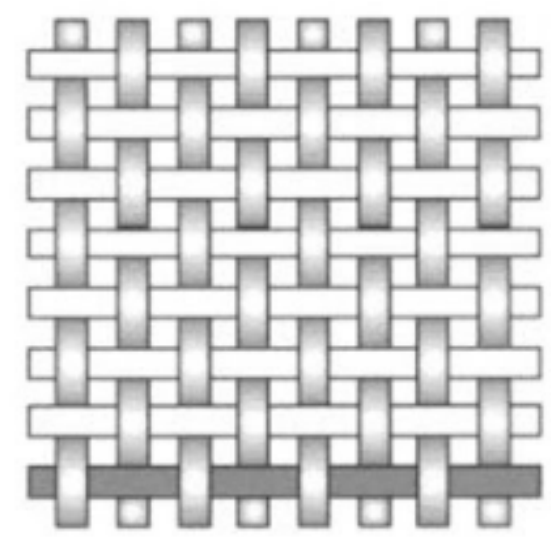

Figure 1 - Webbing pattern configuration [5]

Since the webbing have a complex mechanical behavior, the tests parameters must be studied beforehand. The length, speed and preload were some of the data determined before the experiments. Thus, a methodology was developed based on the existing standards ASTMD6775 [6] and WSTDA-TM-1 [7] applied in studies with elastomers [8] and composite fabrics [9]. Therefore, uncertainties and influences of the input parameters were discarded allowing the correct analysis of the samples.

The tests were performed using an universal testing machine together with a locking equipment for fastening the webbing. The data acquired from the machine were: force, displacement (or elongation of the tape) and duration of the test, since stresses and strains, commonly obtained in these tests with different materials, are difficult to be studied at this stage of the research.

The use of webbing in mooring, safety equipments and even sports practice is commonly observed today. However, during its application, several important factors like rupture load and preload (PL) that alter its behavior are disregarded. The main objective of the research is to determine how the application of PLs modifies the behavior of the webbing and the bursting loads through tests. Since elastomers and polymeric materials undergo changes in their behavior when subjected to cyclic loading [1] and [2], the present work seeks the mechanical characterization of this component.

\section{METHODOLOGY}

In order to perform the experiments, the universal machine Shimadzu AUTOGRAPH AG-X plus (displayed in Figure 2 (c)), whit a $250 \mathrm{kN}$ load cell, was used based on the standards (split drum presented in Figure 2 (a)) and works aforementioned (similarly to a stripe). Prior to the tests, the input parameters were determined to eliminate its influence in the mechanical response. The standards indicate a wide range of values for the parameters testing as well as a variation in the response when modifying the input parameters.

Several tests were performed in order to establish the test parameters. The values that best fit the proposed methodology were:

- Loading speed: $75 \mathrm{~mm} / \mathrm{min}$;

- Sample length: 500mm;

- Preload: three preloads of $70 \%$ of the sample bursting load.

The data acquisition indicated by the standard was very rudimentary and inaccurate for this type of work. According to the standard [1]: "The equipment will be stopped and the distance between the two fine ink marks or pins measured with calipers or other suitable 
measuring device at the load level specified". Therefore, the procedure was changed, obtaining the values of displacement directly from the machine.

Tests were performed using 26 different webbings, each one with 5 samples, manufactured from companies in Brazil, Germany, USA and France. The webbing, shown in Figure 2 (b), composition and materials used are only known by the manufactures and are kept as a secret. NYLON, Poliester and UHMWPE are materials commonly applied in this component

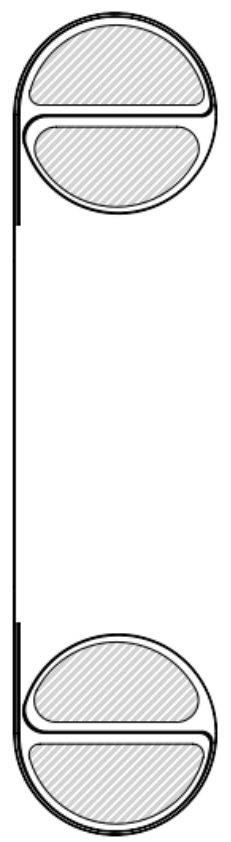

(a)

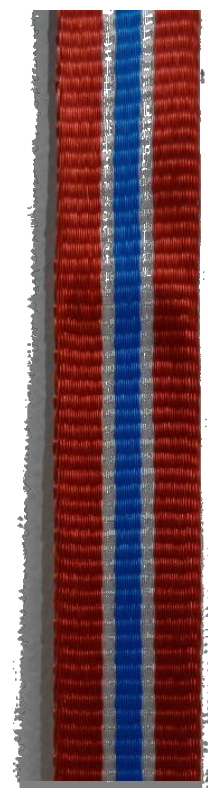

(b)

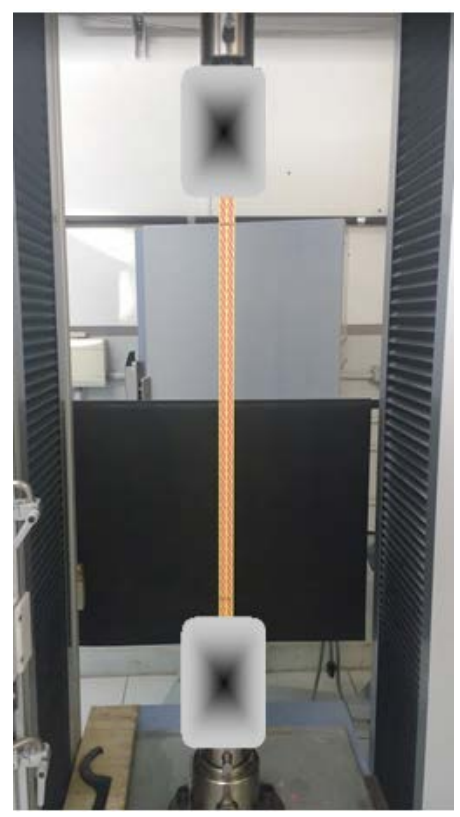

(c)

Figure 2 - (a) Sample fixation, (b) Sample itself and (c) Sample in the machine 


\section{RESULTS}

\subsection{Initial Experiments}

Initially the webbings were tested, without preload, to determine the rupture load. This result can be seen in Figure 3, showing a rupture load of approximately $27 \mathrm{kN}$. A nonlinear behavior in the test, characteristic of this type of material and its construction (Figure 1), is observed. Since the tape is composed of several filaments organized in a pattern, the slippage of these wires until the alignment with the applied load increases the stiffness of the component to the as far as the local fiber rupture, causing overall webbing failure.

Since this type of material changes its behavior with the change of applied forces [10], a test with different preloads was performed. Figure 3 shows the curves of five cycles $(1,2,3$, 5,10 ) of preloads of $70 \%$ of the rupture load (PL70) and the test until failure of cycles 3 and 10. It was verified that this parameter altered the shape of the curve, however, the rupture load was not altered with the use of the PL. In addition, it has been observed that the non-linear effects of the webbing are reduced.

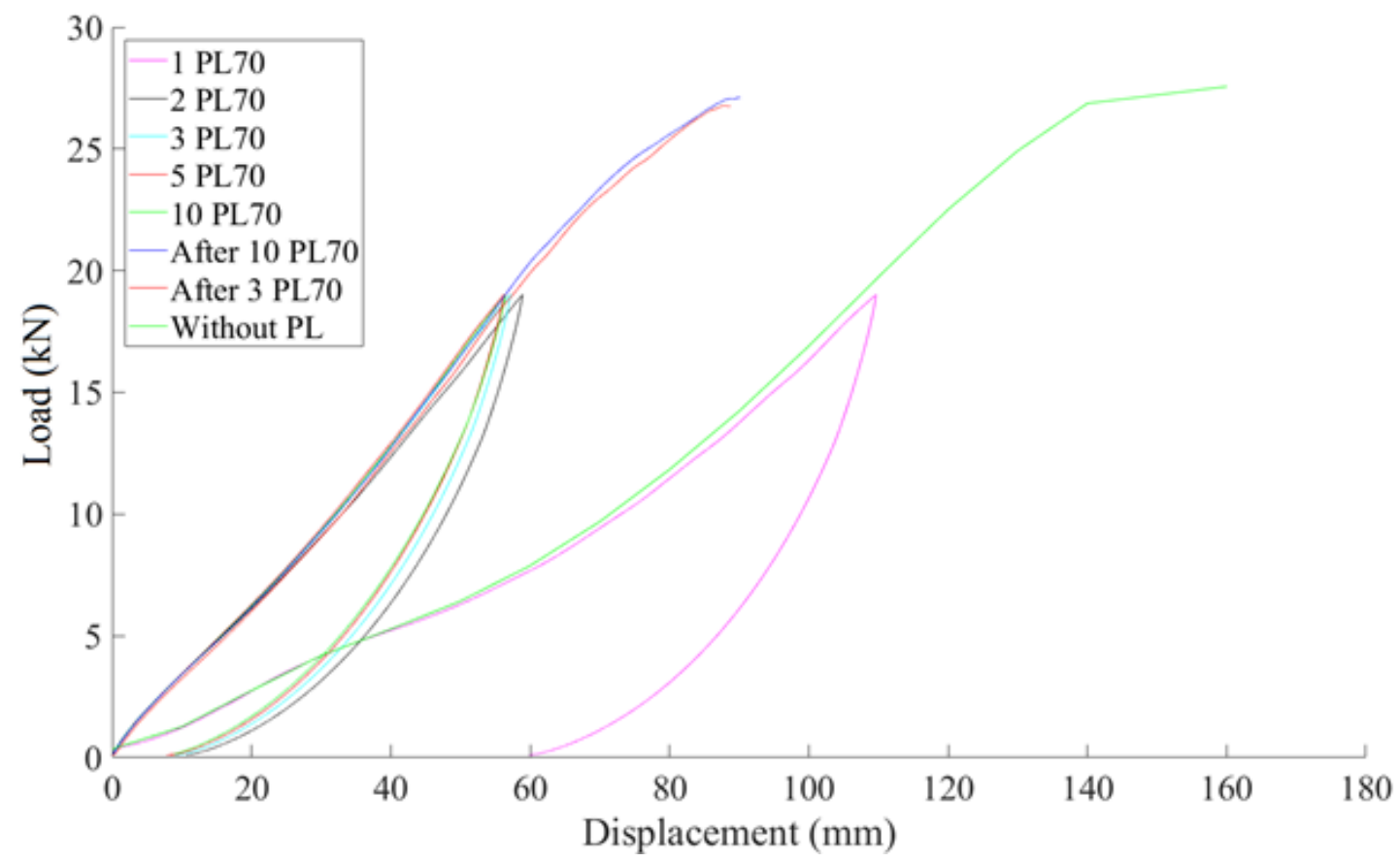

Figure 3 - Comparison between the test without preload and after five cycles of preload.

The change in the slope of the curve indicates the stiffening of the tape. This mechanism is a consequence of the fibers alignment in the loading direction. By the action of the remaining internal friction between fibers and fibers, and fibers and pattern, after discharging, these fibers remain aligned, which causes the increase of stiffness.

It is observed in Figure 3 that the first preload is responsible for most of the fiber alignment and removal of any geometric imperfection presented in the sample. Subsequent PLs have little, if any, effect on the mechanical response of the component. After applying three PL70 there was a stabilization of the tape behavior, i.e., from the 4th PC70 the influence on the final response is insignificant, consequently it was defined that three PC70s were sufficient to prepare the sample for tests and, even, real field use, like sports practice, load transportation and fixing.

\subsection{Webbing Stiffning and Mullins Effect}

After verifying the behavior change of the webbing when applied high preloads, an experiment was carried out to compare this phenomenon with the Mullins Effect (ME) [11]. 
This effect, represented in Figure 4, is characterized by energy conservation (having little hysteresis during cycles). However, the effect of the tapes has a significant hysteresis, according to Figure 5, due to the friction between the fibers. Another difference between the hypothesis is that in ME the loading and unloading cycles break the molecular chains, however, in the components tested these cycles pre-align the fibers in the loading direction and remove any defect or slack between the fibers.

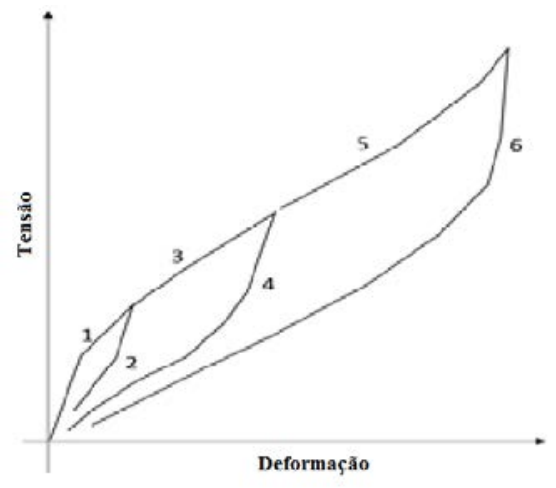

Figure 4 - Mullins effect representation [12].

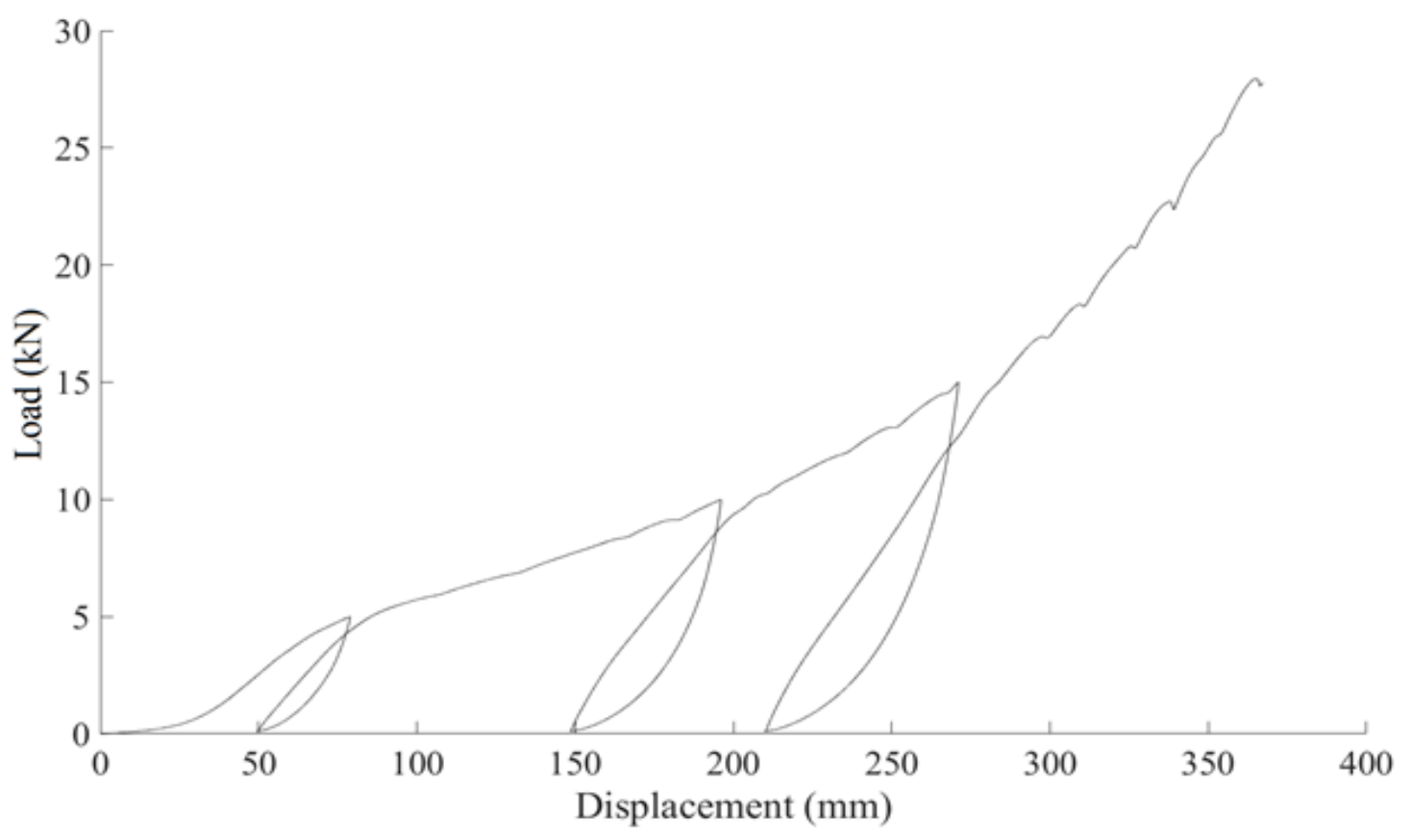

Figure 5 - Webbing test considering the preload cycle.

The experiment was performed using a PL of $0,1 \mathrm{kN}$ to eliminate any gap from the webbing and the test machine. Figure 5 shows three loading cycles increasing $5 \mathrm{kN}$ after every discharging. The new path, considering the new cycle, is different from the initial curve, a consequence from the pattern friction. Once again, no change in the rupture load is observed.

\subsection{Low preload experiments}

Since the product is used in the field in a different manner from that tested, it was necessary to perform an experiment with PL close to the loads used in field. Considering loads of $10 \mathrm{kN}$ during use (less than $50 \%$ of the rupture), the test is important to verify whether there would be alignment during use at the same ratio as with PL70. Therefore, a test was carried out in with 10 preloads of $7 \mathrm{kN}$ (PL7), corresponding to loads used in sports (slackline) and applied in cargo transport. 


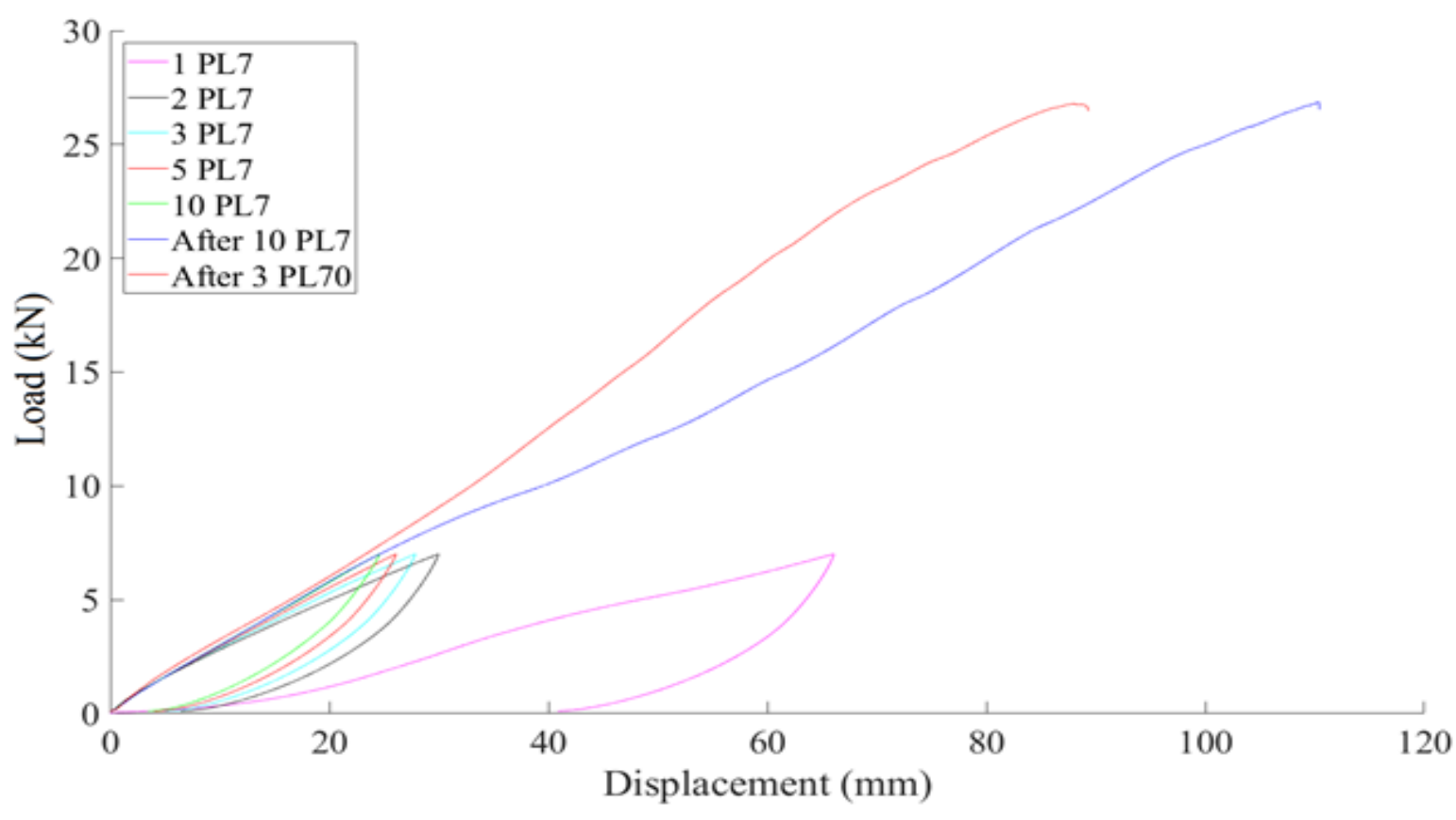

Figure 6 - Comparison from the experiment with preloads of $7 \mathrm{kN}$ and $70 \%$ of the rupture load.

The PL7 mechanical response was compared with 3 PL70. This comparison is shown in Figure 6, demonstrating that the load used in the field is not sufficient to completely align the fibers. Even after the application of 10 PC7, the behavior was not stabilized, that is, more repetitions would be necessary to possibly reproduce the PC70 result. The PL7 sample stiffness was initially similar to PC70, but the lack of complete alignment of the fibers resulted in a different behavior after $20 \mathrm{~mm}$ of displacement. It is also observed that the breaking load remained the same.

\subsection{Tests comparison}

After all the tests were completed, the mechanical responses obtained from the different input parameters were compared in order to highlight the effects previously mentioned. This comparison is shown in Figure 7. The mean curve and every other result were obtained from five samples. Two limits are noticeable: The lower limit (without PL) represents the webbing minimum stiffness while the upper limit (10 PL70) indicates the maximum slope of the curve. Consequently, every result from PL applied will be contained between these limits. 


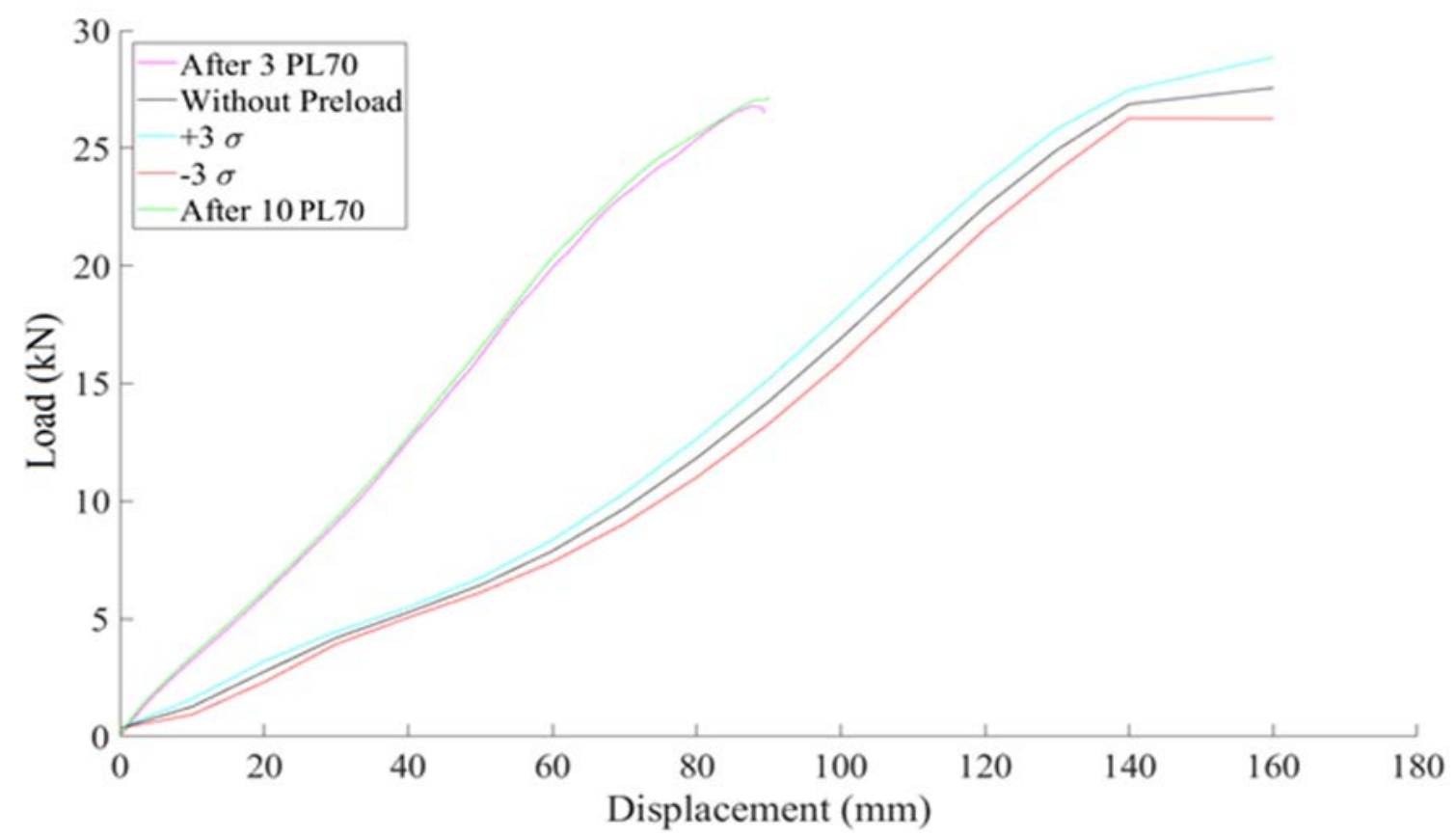

Figure 7 - All experiments rupture curve comparison.

\section{CONCLUSIONS}

An experimental methodology was proposed for polymeric webbing testing based on standards adaptations. The definition of the input parameters proved to be efficient and capable of capturing the effects necessary for the evaluation of the samples mechanical behavior.

After the initial tests, it was observed that with the use of preloads there was a change in the webbing behavior (increase of stiffness). The Mullins effect was compared to the webbing response considering the preload cycle and was shown to be efficient only to analogy purposes. Also, it was evaluated that low preloads do not generate complete fiber alignment nor stabilize the preload cycle. None of the studied cases changed the rupture load, remaining close to the initial test.

\section{REFERENCES}

[1] Mullins, L., Tobin. N. R., 'Stress softening in rubber vulcanizates. Part I. Use of a strain amplification factor to describe the elastic behavior of filler-reinforced vulcanized rubber' 1965.

[2] Roque, R. M., 'Análise teórica e experimental de elastômeros’, Dissertação, (Mestrado em Engenharia Mecânica) - Instituto Superior Técnicc, Universidade Tecnica de Lisboa. Lisboa, Portugal. 2007.

[3] Takashi Ishikawa and Tsu-Wei Chou, 'Nonlinear Behavior of Woven Fabric Composites', Mechanical and Aerospace Engineering Department University of Delaware Newark, Delaware, (Journal of Composite Materials 1983) 17: 399 - American Society for Composites.

[4] C.Z. Paiva Júnior, L.H. de Carvalho, V.M. Fonseca, S.N. Monteiro, J.R.Md'Almeida, 'Analysis of the tensile strength of polyester/hybrid ramie-cotton fabric composites' Polymer Testing - Volume 23, Issue 2, April 2004, Pages 131-135.

[5] Campbell, F. C., 'Manufacturing Processes for Advanced Composites' .Elsevier Ltd, U.K., 2004. Pg.52

[6] ASTM D6775 - 13. Standard Test Method for Breaking Strength and Elongation of Textile Webbing, Webbing and Braided Material, American Society for Testing and Materials, 2017. 
$4^{\text {th }}$ Brazilian Conference on Composite Materials. Rio de Janeiro, July $22^{\text {nd }}-25^{\text {th }}$, 2018

[7] Strength \& Elongation Recommended Test Method for Sling \& Tie Down Webbing, Web Sling and Tie Down Association, Inc., Standard Specification WSTDA-TM-1.

[8] Constitutive modeling of the large strain time-dependent behavior of elastomers J.S.BergströmM.C.Boyce - Volume 46, Issue 5, May 1998 - Journal of the Mechanics and Physics of Solids - J.S.Bergström, M.C.Boyce.

[9] K. Buet-Gautier and P. Boisse. 'Experimental Analysis and Modeling of Biaxial Mechanical Behavior of Woven Composite Reinforcements'. Setembro 2001 Experimental Mechanics (2001) 41: 260.

[10] Iemura. H., 'Structural Stability and Nonlinear Behavior, Vol. I', Department of Civil Engineering Systems, Kyoto University, Kyoto, Japan.

[11] Mullins. L., ' Softening of Rubber by Deformation. Rubber Chemistry and Technology’. March 1969, Vol. 42, No. 1, pp. 339-362.

[12] Dorfmann, A., Ogden, R. W., 'A constitutive model for the Mullins effect with permanent set in particle-reinforced rubber". International Journal of Solids and Structures. 41: 1855-1878. 